\title{
Efficacy and Safety of Ixekizumab in a Randomized, Double-Blinded, Placebo-Controlled, Phase 3b Clinical Trial in Patients With Moderate-to-Severe Genital Psoriasis
}

Caitriona Ryan, ${ }^{1}$ Alan Menter, ${ }^{2}$ Lyn Guenther, ${ }^{3}$ Andrew Blauvelt, ${ }^{4}$ Robert Bissonnette, ${ }^{5}$ Fan Emily Yang, ${ }^{6}$ Alison Potts Bleakman, ${ }^{6}$ David A Amato ${ }^{6}$ Department of Dermatology St Vincent's Hospital, Dublin, Ireland; ${ }^{2}$ Menter Cosmetic Institute, Dallas, TX, USA; ${ }^{3}$ Guenther Research Inc., London, Canada; ${ }^{4}$ Oregon Medical Research Center, Portland, OR, USA;

\section{SYNOPSIS}

- Genital psoriasis is common (up to $60 \%$ ) in patients with plaque

psoriasis
Can have
helth

- Limited data exist from clinical trials on the efficacy of

- Limited data exist from clinical
treatments for genital psoriasis

- Mxekizumab is a high-affinity monoclonal antibody that

treatment of plaque psorias

OBJECTIVE

- To evaluatat the effect of tixekizumab on the severity y f genital
psoriasis compared with placebo oduring 12 weeks of treatment

STUDY DESIGN

IXORA-Q

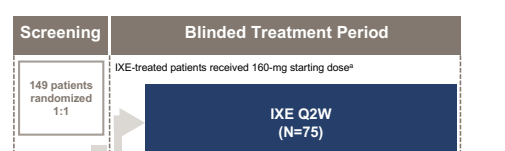

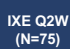

\section{$\underset{\substack{\mathrm{PBO} \\(N=74)}}{(-2)}$}

WEEK 0

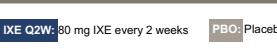

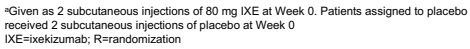

Key Eligibility Criteria

- Inclusion Criteria
- Male or female $\geq 18$-years-old

- Chronic plaque psoriasis for $\geq 6$ months

Plaque psoriasis in a non-genital area

static Physician's Global Assessment (SPGA) of genitalia

Overall SPGA $\geq 3$

Body surface area (BSA) $\geq 1 \%$

Failed to respond to/intolerant of $\geq 1$ topical therapy ${ }^{b}$ for genital

\section{Exlusion Critera}

Recent suicide attempt (\$30 days), suicide risk, or Quick $\left.\mathrm{SR}^{16}\right)$ Item 12 score of 3

Significant uncontrolled cardiovascular, cerebrocar
or other unstable medical or psychiatric conditions

Active or recent infection that would pose an unacceptable risk

to the patient

Received/currently receit
tinea in the genital area

-Received treatment with interleukin-17 (L-17) a the

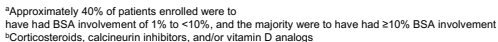

Primary Endpoint

sPGA of Genitali

Measurement of the patient's psoriasis severity in the genital
region at a given time point on a 6-point scale:

\section{0) 1234

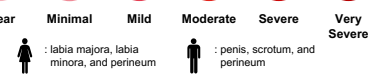

Major Secondary Endpoints

- Proportion of patients achieving overall static physician globa

assessment [SPGA $(0,1)]$
Proportion of patients achieving a 23-point improvement in genit
itch numeric rating scale (gen-itch NRS)

itch numeric rating scale (gen-itch NRS)
Among patients with a baseline score of $\geq 3$

Proportion of patients whose frequency of sexual activity was
never or rarely limited by genital psoriasis

Among patients with a baseline score $\geq 2$

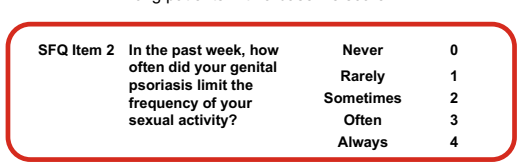

Statistical Analysis

Efficacy: Intent-to-Treat
Population
involvementent $(<10 \%$ or $\geq 10 \%)$

Population All patients who were

randomized
Safety: Safety Population

- Secondary analysis was

Randomized patients who
eceived at least one dose
exact test

Efficacy outcomes: Evalua

RESULTS

\section{Baseline Demographics and Disease}

Characteristics

\begin{tabular}{|l|c|c|}
\hline & $\begin{array}{c}\text { PBO } \\
(\mathrm{N}=74)\end{array}$ & $\begin{array}{c}\text { IXE Q2W } \\
(\mathrm{N}=75)\end{array}$ \\
\hline Age, years & $44.4(12.6)$ & $43.1(13.0)$ \\
\hline Male, $n$ (\%) & $57(77)$ & $56(75)$ \\
\hline Weight, $k$ kg & $95.1(26.3)$ & $91.9(23.1)$ \\
\hline Time since psoriasis onset, years & $16.1(12.5)$ & $16.9(12.8)$ \\
\hline Time since genital psoriasis onset, & $8.3(8.2)$ & $9.3(10.0)$ \\
years
\end{tabular}

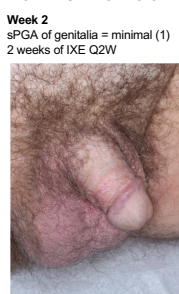

Percentage of BSA involved

BSA 1 to $<10 \%, n$ n $\%)$

BSA $210 \%$, n $(\%)$

SPGA of genitalia

SPGA of genitalia=3, $n(\%)$

SPGA of genitalia=4, $\mathrm{n}(\%)$

SPGA of genitalia=5, $\mathrm{n}(\%)$

SPGA overall

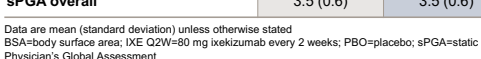

sPGA of Genitalia $(0,1)$ Response Rate

- Percentage of patients achieving clear or almost clear genital
skin was significantly greater for ixekizumab as early as Week 1

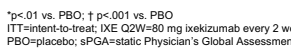

sPGA of Genitalia $(0,1)$ Response Rate by BSA NRI, Blinded Treatment Period, ITT Population

The SPGA of genitalia $(0,1)$ response with ixekizumab at Week
12 was consistent, regardless of the percent BSA involved at

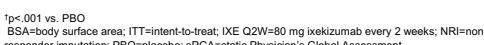

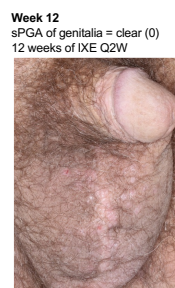

NRI, Blinded Treatment Period, ITT Population
- 7 out of 10 ixekizumab-treated patients achieved clear or almos

clear skin overall at Week 12

Percentage of patients achieving clear or almost clear skin overall
was significantly greater for ixekizumab as early as Week 1
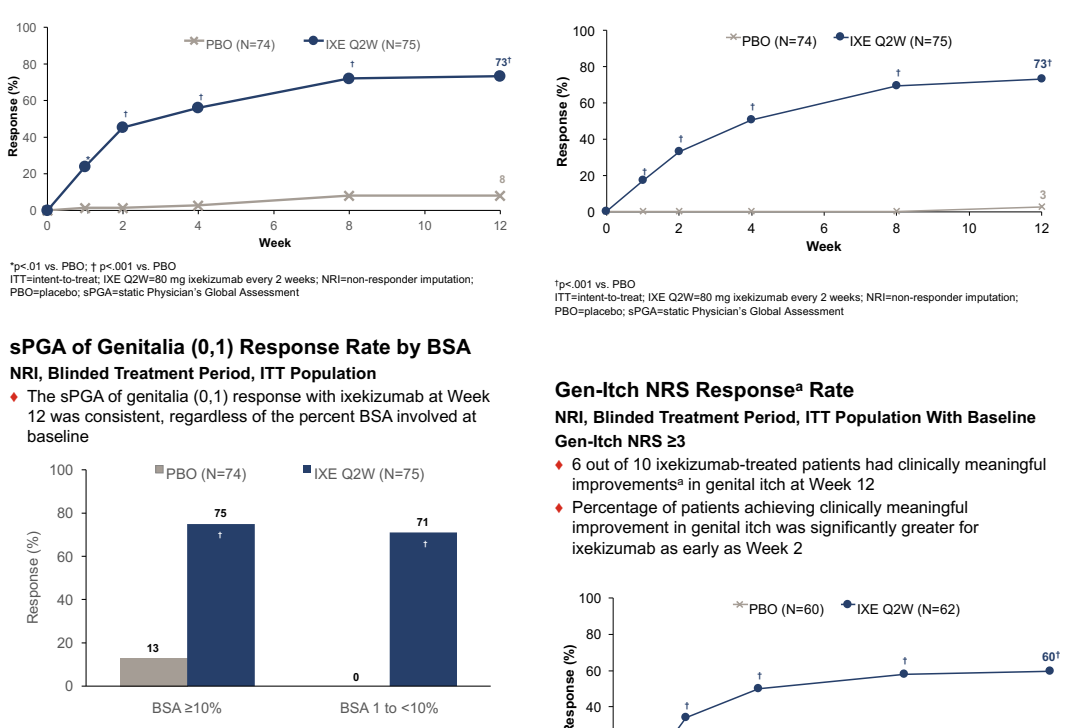

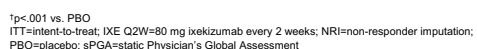

Gen-Itch NRS Responsea Rate

\section{Reviod, ITT Population With Baseline}

Gen-Itch NRS $\geq 3$

- 6 out of 10 ixekizumab-treated patients had clinically meaningfu

improvementsa in genital itch at Week 12

Percentage of patients achieving clinically meaningful
improvement in genital itth was significantly greater for

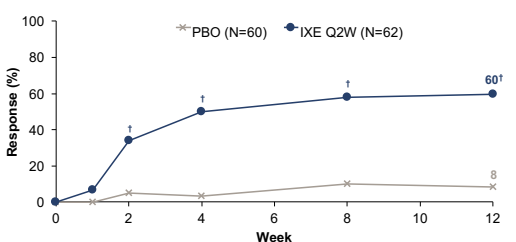

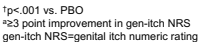

SFQ Item 2 Score $(0,1)$ Response Rate

RI, Blinded Treatment Period, ITT Population With Baseline

2 FQ Item 2 Score $\geq 2$

longer or rarely limited by the impact of genital psatients weres no frequency of sexual activity at Week 12 gential psoriasis on - Percentage of patients who were no longer or rarely limited by the
impact of genital psoriasis on frequency of sexual activity was
significantly greater for ixekizumab as early as Week 1

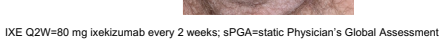

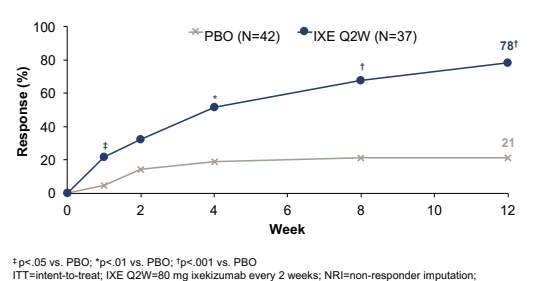

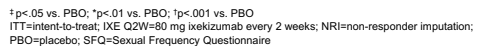

onse Rate

Safety Overview

\begin{tabular}{|l|c|c|}
\hline & $\begin{array}{c}\text { PBO } \\
(\mathrm{N}=74)\end{array}$ & $\begin{array}{c}\text { IXE Q2W } \\
(\mathrm{N}=75)\end{array}$ \\
\hline Overall TEAES & $33(44.6)$ & $42(56.0)$ \\
\hline Mild & $15(20.3)$ & $23(30.7)$ \\
\hline Moderate & $15(20.3)$ & $18(24.0)$ \\
\hline Severe & $3(4.1)$ & $1(1.3)$ \\
\hline Serious adverse event & $1(1.4)^{\mathrm{a}}$ & 0 \\
\hline TEAE related to study treatment & $7(9.5)$ & $14(18.7)$ \\
\hline Discontinuation due to AEs & $5(6.8)^{\mathrm{b}}$ & $1(1.3)^{\mathrm{b}}$ \\
\hline Most common TEAEs & & \\
\hline Upper respiratory tract infection & $5(6.8)$ & $11(14.7)$ \\
\hline Injection-site reactions & $2(2.7)$ & $8(10.7)$ \\
\hline Headache & $4(5.4)$ & $3(4.0)$ \\
\hline Oropharyngeal pain & $2(2.7)$ & $3(4.0)$ \\
\hline Pruritus & $2(2.7)$ & $3(4.0)$ \\
\hline
\end{tabular}

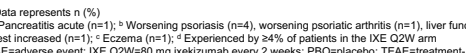

\section{CONCLUSIONS}

Ixekizumab was superior to placebo for the primary an significant improvements versus placebo were

observed as early as Week 1

profile of ixekizumab ${ }^{4-7}$

- Ixekizumab: genita
skin

Improves genital itch

Minimizes how often genital psoriasis limits the

frequency of sexual activity

\section{Disclosures}

D. Amato is a full-time employee of Eli Lilly and Company and

has stocks

This study was sponsored by Eli Lilly and Company. Medical - part of the Envision Pharma Group, and were funded by Eli Lilly and Company

References

1. Ryan C, et al. J Am Acad Dermatol. 2015;72:978-983.
2.Meeuwis KA, et al. Acta Derm Venereol. 2015;95:211-216. 4.Leonardi C, et al. $N$ Eng J Med. 2012; 3666:1190-1199.
5.Gordon KB, et al. J Am Acad Dermatol. 2014;71:1176-1182. 6.Griffiths CE, et al. Lancet. 2015; 3866:541-551.
7.Gordon KB, et al. N Eng J Med. 2016;375:345-356.

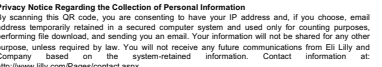

Sponsored by Eli Lilly and Company and/or one of its subsidiaries 